\title{
Profitable Technical Trading Rules For The Austrian Stock Market
}

\author{
Massoud Metghalchi, (E-mail: MetghalchiM@uhv.edu), University of Houston, Victoria \\ Yong Glasure, University of Houston, Victoria \\ Xavier Garza-Gomez, University of Houston, Victoria \\ Chien Chen, University of Houston, Victoria
}

\begin{abstract}
Two moving average technical trading rules for the Austrian stock market are tested. Results indicate that moving average rules do indeed have predictive power and could discern recurringprice patterns for profitable trading. Results also support the hypothesis that technical trading rules can outperform the buy-and-hold strategy. Break-even one-way trading costs are estimated to be between .61 and $2.36 \%$. These break-even costs are larger than recent estimates of actual trading costs, implying profitable trading rules for the Austrian stock market.
\end{abstract}

\section{INTRODUCTION}

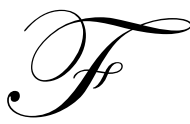

ama (1970) defines an efficient financial market as one in which security prices always fully reflect the available information. Any new information is reflected quickly and instantaneously in prices. Moreover, since news on any company, by definition, is unpredictable (arrives randomly), price changes are also unpredictable or follow a random walk. Fama makes a distinction among three forms of Efficient Market Hypothesis (EMH): (a) a weak form, (b) a semi-strong form, and (c) a strong form. Advocates of the weakform market efficiency hypothesize that investors cannot drive profits above a buy-and-hold strategy using any trading rule that depends solely on past market information such as price or volume. This thus implies that technical trading rules are useless.

After more than three decades of research and literally thousands of journal articles, there still is no consensus among financial economists and practitioners on whether technical trading rules can discern recurring-price patterns for profitable trading. An overwhelming majority of financial economists support the "weak-form" efficient market hypothesis, a reflection of much of earlier research supporting the random walk hypothesis. While the semistrong form of EMH has formed the basis for most empirical research, these studies (Larson 1960, Osborne 1962, Alexander 1964, Granger and Morgenstern 1963, Mandelbrot 1963, Fama 1965, Fama and Blume 1966, Van Horn and Parker 1967, Jensen and Benington 1970) have long supported the weak-form market efficiency.

Since the early-1990s, technical trading however has been enjoying a renaissance both on Wall Street and in academic circles. Several papers have presented evidence that some simple trading rules are useful for predicting stock market returns. Brock, Lakonishok and LeBaron's (1992) study that analyzed moving averages and trading range breaks on the Dow Jones Industrial Index from 1897 to 1985 provides the cornerstone of this new research on technical analysis. In their study, BLL used various short and long moving averages of prices to generate buy and sell signals, and then tested long moving averages of 50,150 and 200 days with short averages of 1,2 and 5 days. BLL pointed out that "all buy-sell differences are positive and the t-tests for these differences are highly significant...." and then concluded that their "results are consistent with technical rules having predictive power." Other researchers have used some variants of BLL's moving averages to investigate whether stock market indices can be predicted by some simple form of technical analysis. Bessembinder and Chan (1995) conclude that the BBL's rules are successful in predicting stock price movement in Japan, Hong Kong, South Korea, Malaysia, Thailand and Taiwan, with the predictability strongest in the last three markets. Ergul, Holmes and Priestley (1997), using daily closing prices of 63 stocks traded on the Istanbul Stock Exchange, conclude that technical analysis on volume can aid the prediction of returns which cannot be predicted by the analysis of past returns in isolation. Pruitt and White (1998), using the 
university of Chicago's CRSP daily data tapes over the 1976-1985 period, conclude that technical trading rules are capable of outperforming a simple buy-and-hold strategy even adjusting for transaction costs. Bessembinder and Chan (1998) confirm the basic BLL results; however, they argue that the BLL results can coexist with the notion of market efficiency when considering transaction costs. Gencay (1998a, 1998b), Ratner and Leal (1999) also support the predictive power of technical trading rules. Kwon and Kish (2002), applying three popular technical trading rules to the NYSE index over the period 1962-1996, conclude that the technical trading rules have the potential to capture profit opportunities over various models when compared to a buy-and-hold strategy. However, in a recent study, Ready (2002) points out that the apparent success of the BLL moving average rules is a spurious result of data snooping and need not persist in the future. Technical trading rules have also been applied to foreign exchange markets. For a survey of technical trading on foreign exchange markets, see studies by Taylor and Allen (1992) and Maillet and Michel's (2000). This paper uses nearly 2 decades of data to investigate whether movements in the Austrian stock market can be predicted by some form of technical analysis.

\section{DATA AND METHODOLOGY}

We use Datastream's daily index prices of the Austrian stock market from January 2, 1990 to May 17, 2006. We compute daily returns as changes in logarithms of the stock index level, and then estimate approximate annualized returns on the basis of 250 trading days per year as exponential of $(250 \mathrm{R})-1$, where $\mathrm{R}$ is the average daily return. For daily interest rate, we use Datastream's daily one month interbank rate, and then divide the daily one-month rate by 365. (We could have divided by 250; however, that would overestimate the returns of various trading strategies vis a vis the buy-and-hold strategy).

Technical analysis is based on the idea that prices move in trends which are determined by the changing attitudes of traders toward various economics, political and psychological forces. As Pring (1991) points out, "the art of technical analysis is to identify trend changes at an early stage and to maintain an investment posture until the weight of evidence indicates that the trend has reversed." One of the most important Trend-Determining Techniques is based on the crossing of two moving average (MA) of prices. According to this rule, buy (sell) signals are emitted when the short short-term moving average exceeds (is less than) the long-term average by a specified percentage. In this study we use long moving averages of 20,50,100, and 200. As for the short moving average, we use 1 day (the raw price index) moving average following the BLL (1992) study. (We also used 5 and 10 days short MA, but the results were not significantly different from 1 day MA.) Thus, a buy signal is emitted when the short moving average breaks the long one from below and a sell signal is emitted when the short moving average breaks the long from above.

We define $\mathrm{P}_{t}$ as the short moving average or the raw index level at time $t$, and define long moving average of $\mathrm{M}$ at time $\mathrm{t}$ as:

$\mathrm{MA}_{\mathrm{t}}(\mathrm{M})=\frac{1}{M} \sum_{i=0}^{M-1} P_{t-i}$

We will test two moving average rules: the standard moving average rule (SMA) and the increasing moving average rule (IMA). As for trading the index, we will be either in the market (buy days) or out of the market (sell days). We assume that a trader following these $M A$ strategies can presumably observe the prices a few minutes prior to the day's close and make the trading decision at the close. If the closing price is above the long moving average, then the trader will be in the market next day by buying the index at the closing price (next day will be a buy day). Next day's return will be the difference between the logarithm of the closing price next day and the logarithm of closing price the previous day. On the other hand, if the closing price is below the long moving average, then we will sell the index at the closing price and will be out of the market next day (a sell day). For the increasing MA rule, the buy days are the same as standard MA rule plus the requirement that the long run MA should be increasing (positive slope). We define mean buy and mean sell returns as follows: 
$\mathrm{X}(\mathrm{b})=\frac{1}{N_{(b)}} \sum R_{b}$

$\mathrm{X}(\mathrm{s})=\frac{1}{N_{(s)}} \sum R_{s}$

where $\mathrm{N}_{(b)}$ and $\mathrm{N}_{(\mathrm{s})}$ are total number of buy and sell days and $\mathrm{R}_{\mathrm{b}}$ and $\mathrm{R}_{\mathrm{s}}$ are daily returns of buy and sell days. We will test whether the returns of any moving average trading rules are greater than a buy-and-hold strategy and whether the mean buy is different than the mean sell. More specifically:

$\mathrm{H}_{0}: X(b)-X(h)=0, X(s)-X(h)=0, X(b)-X(s)=0$

$H_{\mathrm{A}}: X(b)-X(h) \neq 0, X(s)-X(h) \neq 0, X(b)-X(s) \neq 0$,

where $\mathrm{X}(\mathrm{h})$ is the mean return for the buy-and-hold strategy. The test statistic for the mean buy returns over the mean buy-and hold strategy is:

$\mathrm{t}=\frac{X(b)-X(h)}{\sqrt{\operatorname{Var}(b) / N_{b}+\operatorname{Var}(h) / N}}$,

where $\operatorname{Var}(\mathrm{b})$ and $\operatorname{Var}(\mathrm{h})$ are the variance of buy and buy-and-hold returns respectively. The above formula is also used to test the mean sell returns over the mean buy-and-hold strategy and the mean buy returns over the mean sell returns by replacing the appropriate variables in the $\mathrm{t}$-statistic formula.

\section{EMPIRICAL RESULTS}

For the entire sample period, the daily average of buy-and-hold strategy is 0.00023 ( 0.023 percent per day) with a standard deviation of 0.00882 . The t-value for the buy and hold strategy for the entire sample period (4252 observations) is equal to $1.72(0.00023$ divided by $0.00882 / \sqrt{4252})$. The annual average over the entire sample period is $6.24 \%$. In this paper, all t-statistics are compared with the critical t-value of 1.96 at the $5 \%$ level.

Table I summarizes the results of standard moving average trading rules. The rules are described as (1, long, percentage). For each rule we report mean returns on buy days and sell days, standard deviations of returns on buy and sell days, and total number of buy and sell days. The numbers in the parentheses are the t-statistics (equation 4) testing the difference of the mean buy and mean sell from the unconditional 1-day mean and buy-sell from zero.

The first row of Table I reports the results of trading rule of $(1,20,0)$. We will be in the market (buy days) if the MA1 (price level) is greater than MA20 and out of the market (sell days) if MA1 is less than or equal to MA20. For the sake of the space, we have reported only the results for the short moving average of one and long moving average of $20,50,100$ and 200 . We don't show a band of $1 \%$ or $2 \%$, because the results are almost the same as a zero band.

The buy-sell differences (column 4) for moving averages of 20,50 and 100 are positive and their respective t-statistics are highly significant, rejecting the null hypothesis of equality with zero or the equality of mean buy with mean sell. However, the buy-sell differences for the MA200 is not significant, implying that we cannot reject the hypothesis that the mean buy days return is equal to the mean sell days return. Columns 2 and 3 show mean buy returns and mean sell. All of the t-values for the mean buy are positives and are highly significant, rejecting the null hypothesis of equality of the mean buy with the buy and hold mean. For the sells, all the t-values are significant except the MA200, rejecting the null hypothesis of equality of the mean sell with the unconditional mean return. Columns 5 and 6 report the standard deviations of buy days and sell days. The standard deviations for buy days are always 
smaller than those for sell days, implying that the market is less volatile for buy periods than sell periods. Columns 7 and 8 show the number of buys and sells for various rules. In average, following the standard moving average trading rule, we would have 2460 days in the market and 1720 days out of the market.

Table I

\section{Statistical Results for Standard Moving Average (SMA) Rules}

Results are for daily data from 1/2/90 to 5/16/06. Rules are identified as (short, long, band) where short and long are the short and long moving averages, and band is a percentage difference to generate a signal. $\mathrm{N}_{\mathrm{b}}$ and $\mathrm{N}_{\mathrm{s}}$ are the number of buy and sell signals reported in each period. $\mathrm{SD}_{\mathrm{b}}$ and $\mathrm{SD}_{\mathrm{s}}$ are standard deviations of buy and sell signals respectively. The numbers in the parentheses are the t-statistics testing the difference of the mean buy and the mean sell from the unconditional 1-day mean and buy-sell from zero. The numbers marked with asterisks are significant at the 5\% level for a two-tailed test.

\begin{tabular}{|c|c|c|c|c|c|c|c|}
\hline Rules & Buy & Sell & Buy-Sell & $\mathbf{S D}_{\mathbf{b}}$ & $\mathbf{S D}_{\mathbf{s}}$ & $\mathbf{N}_{\mathbf{b}}$ & $\mathbf{N}_{\mathbf{s}}$ \\
\hline SMA $(1,20,0)$ & 0.00092 & -0.00072 & 0.00164 & 0.00720 & 0.01058 & 2460 & 1792 \\
& $(8.28)^{*}$ & $-(3.34)^{*}$ & $(5.68)^{*}$ & & & & \\
\hline SMA $(1,50,0)$ & 0.00075 & -0.00062 & 0.00137 & 0.00714 & 0.01071 & 2511 & 1711 \\
& $(6.98)^{*}$ & $-(2.95)^{*}$ & $(4.64)^{*}$ & & & & \\
\hline SMA(1,100, & 0.00070 & -0.00044 & 0.00114 & 0.00694 & 0.01064 & 2497 & 1675 \\
$0)$ & $(5.89)^{*}$ & $-(2.32)^{*}$ & $(3.85)^{*}$ & & & & 1700 \\
\hline SMA(1, & 0.00050 & 0.00001 & 0.00049 & 0.00703 & 0.00936 & 2372 & \\
$200,0)$ & $(2.56)^{*}$ & $(-1.1)$ & $(1.83)$ & & & & \\
\hline
\end{tabular}

Table II summarizes the results of increasing moving average trading rules. For each rule we report mean returns on buy days and sell days, standard deviations of returns on buy and sell days, and total number of buy and sell days. The numbers in the parentheses are the t-statistics (equation 4) testing the difference of the mean buy and the mean sell from the unconditional 1-day mean and buy-sell from zero.

The results for Table II are very similar to Table I. The buy-sell differences (column 4) are positive and the tstatistics for these differences are highly significant, rejecting the null hypothesis of equality with zero. The mean buy and sell returns are shown in columns 2 and 3. Except for MA200, the t-values for mean buy and mean sell are highly significant, rejecting the null hypothesis that the buy and sell returns equal the unconditional 1-day return. The standard deviations of buy days and sell days are reported in Columns 5 and 6 . The standard deviations for buy days are always smaller than those for sell days. This implies that the market is less volatile for buy periods than sell periods. Columns 7 and 8 report the number of buys and sells for various rules. In average, following the increasing moving average trading rule, we will have 2158 days in the market and 2021 days out of the market. When we compare the number of buy days and sell days in Tables I and II we find that the IMA trading rule produces less buy days than the SMA trading rule.

If technical analysis did not have any power to forecast price movements, then we should observe that the buy days returns do not differ appreciably from the sell days returns, or the mean buy days should not be significantly different than the mean sell days. The results of Tables I and II indicate that the mean buy days is significantly different from the mean sell days for both SMA and IMA trading rules rules. Given the very strong results of Tables I and II, we conclude that technical trading could work and could be superior to the buy-and-hold strategy. 
Table II

Statistical Results for Increasing Moving Average (IMA) Rules

Results are for daily data from 1/2/90 to 5/16/06. Rules are identified as (short, long, band) where short and long are the short and long moving averages and band is a percentage difference to generate a signal. $\mathrm{N}_{\mathrm{b}}$ and $\mathrm{N}_{\mathrm{s}}$ are the number of buy and sell signals reported in each period. $\mathrm{SD}_{\mathrm{b}}$ and $\mathrm{SD}_{\mathrm{s}}$ are standard deviation of buy and sell signals, respectively. The numbers in the parentheses are the t-statistics testing the difference of the mean buy and mean sell from the unconditional 1-day mean and buysell from zero. The numbers marked with asterisks are significant at the $5 \%$ level for a two-tailed test.

\begin{tabular}{|c|c|c|c|c|c|c|c|}
\hline Rules & Buy & Sell & Buy-Sell & $\mathbf{S D}_{\mathbf{b}}$ & $\mathbf{S D}_{\mathbf{s}}$ & $\mathbf{N}_{\mathbf{b}}$ & $\mathbf{N}_{\mathbf{s}}$ \\
\hline IMA(1,20,0) & 0.00139 & -0.00101 & 0.00240 & 0.00692 & 0.01035 & 2208 & 2044 \\
& $(5.76)^{*}$ & $-(4.68)^{*}$ & $(8.81)^{*}$ & & & & \\
\hline IMA(1,50,0) & 0.00101 & -0.00069 & 0.00170 & 0.00707 & 0.01028 & 2205 & 2017 \\
& $(4.00)^{*}$ & $-(3.33)^{*}$ & $(6.18)^{*}$ & & & & \\
\hline IMA(1,100,0 & 0.00086 & -0.00048 & 0.00134 & 0.00689 & 0.01029 & 2236 & 1936 \\
) & $(3.15)^{*}$ & $-(2.67)^{*}$ & $(4.87)^{*}$ & & & & 2089 \\
\hline IMA(1, & 0.00066 & -0.00005 & 0.00071 & 0.00709 & 0.00892 & 1983 & 2 \\
200,0) & $(1.79)$ & $(-1.43)$ & $(2.83)^{*}$ & & & & \\
\hline
\end{tabular}

\section{TRADING STRATEGIES}

We provide some information on the degree to which traders using these technical trading rules can earn trading profits that could beat the buy-and-hold strategy. Given that the mean buy is greater than both the mean sell and the unconditional 1-day mean, the profitability of technical trading rules depends on a trading strategy, especially what position should the trader take when the rule emits sell signals? If the trader does not invest on the sell days, then the trader's return on the sell days will be zero which will result in a mean return of $\left(N_{b} / N\right) * X(b)+\left(N_{s} / N\right) * 0$ for this strategy. In this study we consider two strategies: (1) the trader will be in the stock market when trading rules emit buy signals and be in the money market when trading rules emit sell signals (long/money) and (2) the trader will borrow at the money market rate to double stock investment when trading rules emit buy signals and be in the money market when trading rules emit sell signals (leverage/money). The total trading return on buy days for the leverage/money strategy is $T R_{t}=2 * R_{t}-M_{t}$, where $R_{\mathrm{t}}$ is the index return on day t and $M_{t}$ is the money market return on day t.

For each strategy we estimate the daily return and then subtract from it the daily return from the buy-andhold strategy to get the daily difference return. To test whether the average daily difference is greater than zero, we express the null and alternative hypotheses as follows:

$\mathbf{H}_{\mathbf{0}}:$ ddif $=0$

$\mathbf{H}_{\mathbf{A}}: \operatorname{ddif} \neq 0$

The t-statistic for the above test is:

$\mathrm{t}=\frac{X(\text { ddif })}{\sqrt{\operatorname{Var}(\text { ddif }) / N}}$

where $X(d d i f)$ is the average daily difference of returns of each strategy over the buy-and-hold strategy, $\operatorname{Var}(d d i f)$ is the variance of daily difference returns, and $\mathrm{N}$ is the total number of days. Table III reports the results of the above two strategies for both the SMA and IMA rules.

As shown in panel A of Table III, for both strategies the standard moving average rules beat the buy-andhold strategy. The t-values long/money and for leverage/money are highly significant, rejecting the null hypothesis that the average daily difference is equal to zero. The average standard deviations respectively are 0.00663 and 0.00857 for long/money and leverage/money strategies. These average standard deviations are similar to the standard 
deviation of the buy-and-hold strategy which is 0.00882 . Therefore, both of these two strategies have higher average returns, not higher average risks, thus beating the market as implied by their high and significant t-values.

Panel B of Table III presents the results for increasing moving average rules. Again, using increasing moving average rules and either strategy one (long/money) or strategy two (leverage/money) will beat the buy-and-hold strategy. The t-values for strategy one for strategy two are highly significant, rejecting the null hypothesis that the average daily difference is equal to zero. The average standard deviations are similar to the standard deviation of the buy-and-hold strategy which is 0.00882 . Therefore, both of these two strategies with increasing moving average rules have higher average returns, not higher average risks, thus beating the market as implied by their high and significant t-values.

Advocates of the weak-form market efficiency hypothesize that investors cannot drive profits above a buyand-hold policy using any trading rule that depends only on past market information such as price. The results of Table III cast doubt on the weak-form market efficiency and support the notion that moving average trading rules contain substantial information to predict changes in the Austrian stock index.

Table III

Statistical Results for Trading Strategies

\begin{tabular}{|c|c|c|c|c|}
\hline \multirow{2}{*}{\multicolumn{5}{|c|}{$\begin{array}{l}X(\text { ddif }) \text { and } S D(\text { ddif }) \text { are the average and the standard deviation of daily differe } \\
\text { buy-and-hold strategy. The numbers in the parentheses are the t-statistics wh } \\
\text { from zero. The numbers marked with asterisks are significant at the } 5 \% \text { level. } \\
\text { Panel A: Standard Moving Average Rules }\end{array}$}} \\
\hline & & & & \\
\hline & \multicolumn{2}{|c|}{ Strategy 1: Long/Money } & \multicolumn{2}{|c|}{ Strategy 2: Leverage/Money } \\
\hline Rules & $\mathbf{X}($ ddif $)$ & SD(ddif) & X(ddif) & SD(ddif) \\
\hline $\operatorname{SMA}(1,20,0)$ & $\begin{array}{c}0.00036 \\
(3.43)^{*}\end{array}$ & 0.00688 & $\begin{array}{c}0.00083 \\
(6.17) * \\
\end{array}$ & 0.00878 \\
\hline $\operatorname{SMA}(1,50,0)$ & $\begin{array}{l}0.00031 \\
(2.95)^{*}\end{array}$ & 0.00683 & $\begin{array}{c}0.00069 \\
(5.13) *\end{array}$ & 0.00877 \\
\hline SMA $(1,100,0)$ & $\begin{array}{l}0.00024 \\
(2.27)^{*}\end{array}$ & 0.00677 & $\begin{array}{l}0.00059 \\
(4.43)^{*}\end{array}$ & 0.00864 \\
\hline SMA $(1,200,0)$ & $\begin{array}{c}0.00006 \\
(0.63) \\
\end{array}$ & 0.00605 & $\begin{array}{l}0.00029 \\
(2.29)^{*}\end{array}$ & 0.00809 \\
\hline Average SMA & 0.00024 & 0.00663 & 0.00060 & $\mathbf{0 . 0 0 8 5 7}$ \\
\hline $\begin{array}{c}\text { Average annual } \\
\text { difference }\end{array}$ & $6.25 \%$ & & $16.22 \%$ & \\
\hline \multicolumn{5}{|c|}{ Panel B: Increasing Moving Average Rules } \\
\hline $\operatorname{IMA}(1,20,0)$ & $\begin{array}{c}0.00055 \\
(5.02)^{*}\end{array}$ & 0.00720 & $\begin{array}{c}0.00121 \\
(9.06)^{*}\end{array}$ & 0.00874 \\
\hline $\operatorname{IMA}(1,50,0)$ & $\begin{array}{c}0.00040 \\
(3.63)^{*}\end{array}$ & 0.00712 & $\begin{array}{c}0.00087 \\
(6.44)^{*}\end{array}$ & 0.00875 \\
\hline IMA(1,100,0) & $\begin{array}{c}0.00029 \\
(2.68)^{*}\end{array}$ & 0.00701 & $\begin{array}{c}0.00070 \\
(5.23) *\end{array}$ & 0.00863 \\
\hline $\operatorname{IMA}(1,200,0)$ & $\begin{array}{c}0.00010 \\
(1.04) \\
\end{array}$ & 0.00639 & $\begin{array}{c}0.00038 \\
(2.99)^{*} \\
\end{array}$ & 0.00808 \\
\hline Average IMA & 0.00034 & 0.00693 & 0.00079 & $\mathbf{0 . 0 0 8 5 5}$ \\
\hline $\begin{array}{c}\text { Average annual } \\
\text { difference }\end{array}$ & $8.75 \%$ & & $21.83 \%$ & \\
\hline
\end{tabular}


In conclusion, we have identified, based on technical trading, two strategies (Long/money and leverage/money) which significantly beat the buy-and-hold strategy. Although the discovery of profitable trading rules may be helpful in understanding market dynamics, traders may not be able to exploit these rules without considering transaction costs. In order to account for transaction costs for these two strategies, we report in Tables IV and V the "break-even" transaction costs, which are the one-way percentage cost that eliminates the additional return from technical trading rules. We also report annual transaction costs assuming that one-way transaction cost is $0.5 \%$.

The first column of Table IV identifies trading rules, and the second column is the average daily difference returns between strategy one (Long/money) and the buy-and-hold strategy. In column 3, we obtain the annualized excess returns as exponential of (excess return * 250) -1 . Column 4 reports total trades, numbers of in and out of the market signals, or total frequency of transactions, implied by a specific trading rule. In column 5 , we report average trade per year or total trades divided by 16.46 years which is the number of years under consideration. Column 6 reports one-way "break-even" transaction cost or annual excess return divided by average annual trades. One-way transaction cost is assumed to be the same for buying and selling the index. Finally, in the last column we estimate annual transaction costs assuming that one-way transaction cost is $0.5 \%$. We believe that the choice of $0.5 \%$ one-way transaction cost seems very conservative and realistic given the estimate of $0.26 \%$ one-way transaction cost for the DJIA index by Knez and Ready (1996), the estimates of $0.24 \%$ to $0.26 \%$ one-way equity trading cost for institutional traders by Bessembinder and Chan (1995), and its own estimate of $0.25 \%$ one-way trading cost by Wells Fargo Nikko Investment (Kroner 1995).

Table IV

Break-Even Trading Costs for Strategy 1

\begin{tabular}{|c|c|c|c|c|c|c|}
\hline \multirow{2}{*}{\multicolumn{7}{|c|}{$\begin{array}{l}X(d d i f) \text { is the average daily difference betwee } \\
\text { table IV. Annual Excess return is } \operatorname{EXP}(X(d d i \\
\text { from in and out of the market. Trade per year } \\
\text { ratio of annual excess return over trades per ye } \\
\text { Panel A: Standard Moving Average Rules }\end{array}$}} \\
\hline & & & & & & \\
\hline Rules & $\begin{array}{l}\text { Strategy } 1 \\
\text { X(ddif) }\end{array}$ & $\begin{array}{c}\text { Annual Excess } \\
\text { Return \% }\end{array}$ & $\begin{array}{l}\text { Total } \\
\text { Trades }\end{array}$ & $\begin{array}{l}\text { Trades } \\
\text { Per year }\end{array}$ & $\begin{array}{c}\text { One way } \\
\text { Break-even } \\
\text { Costs } \% \\
\end{array}$ & $\begin{array}{c}\text { Annual costs } \% \\
\text { Cost per trade= } \\
.5 \%\end{array}$ \\
\hline $\operatorname{SMA}(1,20,0)$ & 0.00036 & $9.48 \%$ & 364 & 22.11 & $0.43 \%$ & 11.06 \\
\hline SMA $(1,50,0)$ & 0.00031 & $8.06 \%$ & 158 & 9.60 & $0.84 \%$ & 4.80 \\
\hline SMA $(1,100,0)$ & 0.00024 & $6.12 \%$ & 114 & 6.93 & $0.88 \%$ & 3.46 \\
\hline SMA $(1,200,0)$ & 0.00006 & $1.49 \%$ & 84 & 5.10 & $0.29 \%$ & 2.55 \\
\hline Average & 0.00024 & $6.29 \%$ & 180 & 10.94 & $0.61 \%$ & $5.47 \%$ \\
\hline \multicolumn{7}{|c|}{ Panel B: Increasing Moving Average Rules } \\
\hline $\operatorname{IMA}(1,20,0)$ & 0.00055 & 0.1474 & 326 & 19.81 & $0.74 \%$ & 9.90 \\
\hline $\operatorname{IMA}(1,50,0)$ & 0.00040 & 0.1044 & 186 & 11.30 & $0.92 \%$ & 5.65 \\
\hline IMA $(1,100,0)$ & 0.00029 & 0.0754 & 94 & 5.71 & $1.32 \%$ & 2.86 \\
\hline $\operatorname{IMA}(1,200,0)$ & 0.00010 & 0.0263 & 76 & 4.62 & $0.57 \%$ & 2.31 \\
\hline Average & 0.00034 & $8.84 \%$ & 171 & 10.36 & $0.89 \%$ & $5.18 \%$ \\
\hline
\end{tabular}

The average break-even one-way trading costs in column 6, which would just eliminate excess returns of strategy 1 , are between $0.61 \%$ and $0.89 \%$ for SMA and IMA respectively. One-way breakeven costs for IMA rules are higher than those of SMA rules. We believe that these break-even one-way trading costs are just a bit larger than the recent estimates of actual trading costs of $0.25 \%$, especially for the IMA rules. If a trader's one-way transaction cost is below the break-even transaction costs of Table IV, the trader can use either IMA rule or SMA rule and adopt strategy 1 (long \money) and beat the buy-and-hold strategy even considering transaction costs. The extra profits over the buy-and-hold strategy will be higher for IMA rules. The last column of Table IV also reports average annual costs 
of trading in and out of the market assuming a one-way trading cost of $0.5 \%$. These annual trading costs are much lower than excess returns from using trading rules (as shown in column 3), implying profitable technical trading for the Austrian stock index even when considering transaction costs.

Table V

Break-Even Trading Costs for Strategy 2

\begin{tabular}{|c|c|c|c|c|c|c|}
\hline \multirow{2}{*}{\multicolumn{7}{|c|}{$\begin{array}{l}X(\text { ddif }) \text { is the average daily difference betwee } \\
\text { table IV. Annual Excess return is } \operatorname{EXP}(X(d d) \\
\text { from in and out of the market. Trade per year } \\
\text { ratio of annual excess return over trades per ye } \\
\text { Panel A: Standard Moving Average Rules }\end{array}$}} \\
\hline & & & & & & \\
\hline Rules & $\begin{array}{c}\text { Strategy } 2 \\
\text { X(ddif) }\end{array}$ & $\begin{array}{c}\text { Annual Excess } \\
\text { Return } \%\end{array}$ & $\begin{array}{c}\text { Total } \\
\text { Trades }\end{array}$ & $\begin{array}{c}\text { Trades } \\
\text { Per year }\end{array}$ & $\begin{array}{c}\text { One way } \\
\text { Break-even } \\
\text { Costs \% } \\
\end{array}$ & $\begin{array}{c}\text { Annual costs \% } \\
\text { Cost per trade= } \\
.5 \%\end{array}$ \\
\hline $\operatorname{SMA}(1,20,0)$ & 0.00083 & $23.06 \%$ & 364 & 22.11 & $1.04 \%$ & 11.06 \\
\hline $\operatorname{SMA}(1,50,0)$ & 0.00069 & $18.83 \%$ & 158 & 9.60 & $1.96 \%$ & 4.80 \\
\hline $\operatorname{SMA}(1,100,0)$ & 0.00059 & $15.96 \%$ & 114 & 6.93 & $2.30 \%$ & 3.46 \\
\hline SMA $(1,200,0)$ & 0.00029 & $7.52 \%$ & 84 & 5.10 & $1.47 \%$ & 2.55 \\
\hline Average & 0.00060 & $16.34 \%$ & 180 & 10.94 & $1.70 \%$ & $5.47 \%$ \\
\hline \multicolumn{7}{|c|}{ Panel B: Increasing Moving Average Rules } \\
\hline $\operatorname{IMA}(1,20,0)$ & 0.00121 & 0.3547 & 326 & 19.81 & $1.79 \%$ & 9.90 \\
\hline $\operatorname{IMA}(1,50,0)$ & 0.00087 & 0.2430 & 186 & 11.30 & $2.15 \%$ & 5.65 \\
\hline IMA $(1,100,0)$ & 0.00070 & 0.1909 & 94 & 5.71 & $3.34 \%$ & 2.86 \\
\hline $\operatorname{IMA}(1,200,0)$ & 0.00038 & 0.0994 & 76 & 4.62 & $2.15 \%$ & 2.31 \\
\hline Average & 0.00079 & $22.20 \%$ & 171 & 10.36 & $2.36 \%$ & $5.18 \%$ \\
\hline
\end{tabular}

Table $\mathrm{V}$ is the same as Table IV except that it presents the results of strategy two (leverage/money). The average break-even one-way trading costs in column 6 , which would just eliminate excess returns of strategy 2, are between $1.70 \%$ and $2.36 \%$ for SMA and IMA respectively. One-way breakeven costs for IMA rules are higher than those of SMA rules. We believe that these break-even one-way trading costs are much larger than the recent estimates of actual trading costs of $0.25 \%$ especially for the IMA rules. With such a high break-even cost a trader can use either IMA rule or SMA rule and adopt strategy 2 (leverage/long) and beat the buy-and-hold strategy even considering transaction costs. The extra profits over the buy-and-hold strategy will be higher for IMA rules. The last column of Table $\mathrm{V}$ also reports average annual costs of trading in and out of the market assuming a one-way trading cost of $0.5 \%$. These annual trading costs are much lower than excess returns from using trading rules (as shown in column 3 ), implying profitable technical trading for the Austrian stock index even when considering transaction costs. In summary, our results provide support for technical trading rules that can be exploited.

\section{CONCLUSIONS}

Several papers have recently presented evidence that some simple trading rules are useful for predicting stock market returns. This paper investigates three moving average trading rules for the Austrian Stock market over the period 1/2/1990 -5/17/2006. Overall, results of this study provide strong support for the technical trading rules we have explored. If technical analysis does not have any power to forecast price movements, then we should observe that buy days returns do not differ appreciably from sell days returns. Our results show that almost all buy-sell differences are positive and the t-statistics for these differences are highly significant, rejecting the null hypothesis of equality of buy days returns with sell days returns. Our results also indicate that moving average rules do indeed have predictive power and can discern recurring-price patterns for profitable trading. Given this predictive power of technical analysis, we asked whether we can design various trading strategies to beat the buy-and-hold strategy. Our 
results on trading strategies support the hypothesis that technical trading rules can outperform the buy-and-hold strategy. The two strategies we developed can beat the-buy-and-hold strategy over the period under consideration. Although the discovery of profitable trading rules may be helpful in understanding market dynamics, traders must also consider transaction costs. We calculated the break-even one-way trading costs for both strategies, which significantly beat the buy-and-hold strategy over the 16.5-year period. Our results for the breakeven cost are large compared to the estimated actual trading cost of $0.5 \%$. We thus conclude that technical trading rules have predictive power and may be used to design a trading strategy that will beat the buy-and-hold strategy in the Austrian stock market. The observation that technical trading rules have predictive power for changes in the Austrian stock market is consistent with the weak-form market inefficiency.

\section{REFERENCES}

1. Alexander S. Price Movements in Speculative Markets: Trends or Random Walks, Industrial Management Review, 1964, 2, pp. 25-46.

2. Bessembinder H. and Chan K., The Profitability of Technical Trading Rules in the Asian Stock Markets, Pacific-Basin Finance Journal, 1995, 3, pp. 257-284.

3. Bessembinder H. and Chan K., Market Efficiency and Returns to Technical Analysis, Financial Management, 1998, 27, (2), pp. 5-17.

4. Brock W., Lakonishok, J., and LeBaron B., Simple Technical Trading Rules and the Stochastic Properties of Stock Returns, Journal of Finance, 1992, 47, pp. 1731-64.

5. Ergul A, Holmes P., and Priestley R., Technical Analysis, Trading Volume and Market Efficiency: Evidence from an Emerging Market, Applied Financial Economics, 1997, 7, pp. 361-65.

6. Fama E., The Behavior of Stock Market Prices, Journal of Business, 1965, 38, pp. 34-105.

7. Fama E., Efficient Capital Markets: A review of theory and empirical work, Journal of Finance, 1970, 25, pp.383-417.

8. $\quad$ Fama E. and Blume M., Filter Rules and Stock Market Trading Profits, Journal of Business, 1966, 39, pp. 226-341.

9. Gencay R., Optimization of Technical trading strategies and profitability in Security Markets, Economics Letters, 1998a, 59 (2), pp. 249-254.

10. Gencay R., The Predictability of Security Returns with Simple Technical Trading Rules, Journal of Empirical Finance, 1998b, 5 (4), pp. 347-359.

11. Granger C. and Morgenstern O., Spectral Analysis of New York Stock Market Prices, Kyklos, 1963, 16, pp. $1-27$.

12. Jensen M. and Benington G., Random Walks and Technical Theories: Some Additional Evidence, Journal of Finance, 1970, 25, pp. 469-82.

13. Knez P.J. and Ready M.J., Estimating the Profits from Trading Strategies Review of Financial Studies, 1996, 9, pp. 1121-64.

14. Kroner, K., Comments on: Do the profits from Technical trading Rules Reflect Inefficiencies?, mimeo, Wells Fargo Nikko Investment Advisors Advanced Strategy Group, San Francisco 1995.

15. Kwon K. and Kish R., (2002). Technical Trading Strategies and Return Predictability: NYSE, Applied Financial Economics, 2002, 12, pp. 639-53.

16. Larson A., Measurement of Random Process in Futures Prices, Food Research Institute, 1960, 1, pp. $313-24$.

17. Maillet B. and Michel T., Further Insights on the Puzzle of Technical Analysis Profitability, The European Journal of Finance, 2000, 6, pp. 196-224.

18. Mandelbrot B., The Variation of Certain Speculative Prices, Journal of Business, 1963, 36, pp. 394-419.

19. Osborne M., Periodic Structure in the Brownian Motion of Stock Prices, Operations Research, 1962, 10, 345-79.

20. Pring M.J., Technical Analysis: Explained, McGraw-Hill Co., 1991.

21. Pruitt S. and White R., The CRISMA Trading System: Who Says Technical Analysis Can't Beat the Market? Journal of Portfolio Management, 1998, 14, (3), pp. 55-58.

22. Ratner M. and Leal R.P.C., Test of Technical Trading Strategies in the Emerging Equity Markets of Latin America and Asia Journal of Banking and Finance, 1999, 23 (1), pp. 1887-1905.

23. Ready M., Profits from Technical Trading Rules, Financial Management, Autumn 2002, pp. 43-61. 
24. Taylor M. and Allen H., The Use of Technical Analysis in the Foreign Exchange market, Journal of International Money and Finance, 1992, 11, pp. 304-314.

25. Van Horn J.C. and Parker G.C., The Random Walk Theory: an Empirical Test, Financial Analyst Journal, 1967, 23, pp. 87-92.

\section{NOTES}

